\title{
A Comparative Study of Weather Forecasting Simulation Models through Sensors for Accurate Monsoon Predictions in the Indian Ocean
}

\author{
Satyasundar Mallick, Monideepa Roy
}

\begin{abstract}
When Monsoon depressions form over the seas, the Moderate Resolution Imaging Spectroradiometer (MODIS) provides humidity and high-horizontal resolution temperature details about the depressions. These high-resolution satellite data related to temperature and humidity can improve the poor predicting rate of depressions ${ }^{[1]}$. Using three-dimensional variational data assimilation (3DVAR) and with the help of humidity profiles along with MODIS temperature. We can achieve an advanced prospect of detection and a larger value of (ETS) equitable threat score observed over 48 hours collected precipitation with respect to the control run. The 3DVAR assimilation of Doppler Weather Radar wind data associated with Indian Meteorological Department (IMD) surface data and upper air data helped in the improvements in the simulation of strong gradients associated with horizontal wind speed ,higher warm core temperature, high vertical velocity \& better precipitation and spatial distribution. ${ }^{[2]}$. The effect of Spectral sensor microwave imager (SSM/I), humidity profiles, use of Advanced TIROS Vertical Sounder (ATOVS) temperature and total precipitable water (TPW) helped in improving the "forecast impact" parameters of "bias score" and "equitable threat score" with respect to the assimilation of satellite observation ${ }^{[3]}$. In this paper we have discussed a comparative study of different proposed techniques to analyze its effects in improving the low prediction rates of depressions.
\end{abstract}

Keywords: MODIS, 3DVAR, ATOVS, TPW, monsoons depressions, prediction rates

\section{INTRODUCTION}

Agriculture is the most significant sector of the Indian Economy. The agricultural sector provides 18 per cent of the India's GDP \& offers employment to around $50 \%$ of the country's workforce. So, rainfall and tropical cyclones have a major impact upon the agricultural sector. The Indian summer monsoon rainfall is dependent on the longevity and frequency of monsoon disturbances or depressions which form over the Arabian Sea and the Bay of Bengal. Hence depressions play a vital and important role in the time and space distribution of

Revised Manuscript Received on October 10, 2020.

* Correspondence Author

Satyasundar Mallick*, School of Computer Engineering, KIIT University

Monideepa Roy, School of Computer Engineering, KIIT University

(C) The Authors. Published by Blue Eyes Intelligence Engineering and Sciences Publication (BEIESP). This is an open access article under the CC BY-NC-ND license (http://creativecommons.org/licenses/by-nc-nd/4.0/) the rainfall and need to be simulated and examined in a better way. An accurate numerical prediction requires very accurate initial parameters and conditions. Some common drawbacks in the forecast of tropical cyclone are mainly related to the deficit of observational data, and incorrect assimilation of available data in an existing numerical model. We can get accurate and improved initial conditions by assimilating and ingesting high resolution meteorological observations with respect to the initial analysis using Three-Dimensional Variational data assimilation [1][6][7]. Mostly these monsoon depressions are formulated in the data sparse oceanic areas, so it is highly important to assimilate the satellite observations processed into the numerical model to calculate better forecasts with better analysis. The basic goal of this approach is to calculate the impact of ingestion and assimilation of input parameters in MODIS observation in the forecast of a monsoon depression formed over India with the use of a meso-scale approach. The main aim of the 3DVAR system is to calculate an optimal estimate of the correct state of the atmosphere at any specific time with the help of the cost function ${ }^{[4]}$. Another method to enhance the initial parameters is by ingesting and assimilating non-conventional high-resolution observations like satellites along with DWR observations successfully processed into the numerical implemented model. Because of the absence of input parameters, it may lead to the fact that the strength and the centre of the cyclonic vortex are not properly signified. By modifying the initial weak cyclonic vortex along with a synthetic vortex, which is specified at the correct location later on, the initial parameters can also be enhanced. In 1990 , Stauffer and Seaman proposed Newtonian relaxation or nudging methods and in 1992, Parrish and Derbe proposed variational (VAR) data assimilation methods, which are the frequently used techniques for data assimilation to enhance the initial parameters. Despite its simplicity, the nudging method has limitations such as the inability of directly incorporating variables such as rainfall, radar reflectivity and radiance. These parameters can be utilized into the numerical model by the Three-dimensional methods and Four-dimensional Variational methods (3DVAR, 4DVAR). In recent years, several studies have used the 3DVAR assimilation methods to get more accurate predictions of weather conditions.

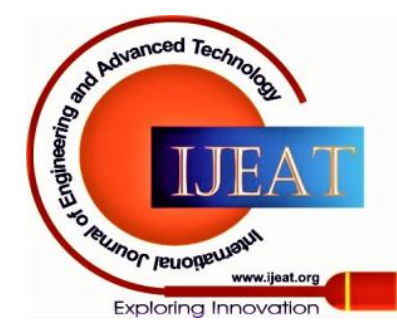


${ }^{[8][9][10]}$.By decoding the impact of the assimilation of the ATOVS temperature with its, humidity profiles , SSM/I ,TPW on the simulation of a depression using 3DVAR and Forecast (WRF) model, it is found that the "forecast impact" parameter which is calculated for the wind speed offers a good evidence of the optimistic impact.

In this paper we have compared the results of the impacts of the assimilation of multiple proposed techniques. The rest of the paper is prepared as follows: Section 2 is a review of the existing techniques, Section 3 explains the model descriptions and numerical experiments, Section 4 discusses the results, Section 5 is a comparative study and Section 6 is the conclusion.

\section{A REVIEW OF EXISTING TECHNIQUES}

\section{DVAR AND 4DVAR APPROACHES:}

During the past years, both 3DVAR and 4DVAR variational more to get improvised initial analysis (Lorenc et al. 2000, Parrish and Derber 1992). The common aim of the 3DVAR data assimilation system is to make an optimization estimate of the current state of the atmosphere at any specific analysis time with respect to the iterative solution of the recommended cost function J(x) (Ide et al. 1997).

$$
J(x)=J^{b}+J^{0}=1 / 2\left(x-x^{b}\right)^{T} B^{-1}\left(x-x^{b}\right)+1 / 2\left(y-y^{0}\right)^{T}(E+F)^{-1}\left(y-y^{0}\right)
$$

where

E: Observation (instrumental)

B: Background

F: Representivity error of covariance matrices.

$H$ is used for transformation of the grid-point analysis ' $\mathrm{x}$ ' mapped into observation space $\mathrm{y} 1 / 4$.

$\mathrm{H}_{\mathrm{x}}$ is used for comparison with respect to observations.

$\mathrm{x}^{\mathrm{b}}$ is the background forecast or previous forecast and $\mathrm{y}^{\mathrm{o}}$ is the observations.

The 3DVAR technique gives an analysis of the actual state $x$ that optimizes the function $\mathrm{J}(\mathrm{x})$. Minimization of cost function $\mathrm{J}(\mathrm{x})$ is done though an iteration process, which represents an a posteriori maximum likelihood estimate of the actual state of the atmosphere ${ }^{[4],[5]}$.

\section{Satellite data for assimilation}

SSM/I total precipitable water:

$\mathrm{SSM} / \mathrm{I}$ experiment receives the total precipitable water details from the SSM/I satellite for the data. The SSM/I, which is a polar orbiting satellite with a period of around $102 \mathrm{~min}$, and swath width of about $1,400 \mathrm{~km}$ and a mean altitude of approximately $830 \mathrm{~km}$. it is a four-frequency and conical scanning passive microwave radiometer having resolution of $25 \mathrm{~km}$. The details of the description of the SSM/I instrument is available in Hollinger (1989) ${ }^{[3]}$. For the reclamation of SSM/I data products the version-five multiple stages regression algorithm used .

Advanced TIROS vertical sounder:

ATOVS is a sounding instrument package, and in the method associated root means square error (RMSE), when validated against near radiosonde observations, was less than ten percentage.The data from ATOVS has undergone quality-control and has been assembled into discrete data sets. The calibration information and the information of the location on Earth are appended to this data. data assimilation methodologies have been utilised more and validation by Rajan et al. (2002) they found that the

\section{MODEL DESCRIPTION AND NUMERICAL EXPERIMENTS}

The results of the three assimilation models are explained here. The First model ${ }^{[1]}$ was related with WRF Version 2.2 and NCAR. For a single domain, this model configured having 28 layers (vertical) and with $36 \mathrm{~km}$ grid spacing (horizontal).The grid dimension related with 119 x 129 grid cells in the north-south and east-west directions.

The NCEP-FNL data presented at a time resolution of 6 hours horizontal resolution with $1^{\circ} \times 1^{\circ}$ latitude/longitude used to improve the initial with lateral boundary conditions .With the help of MODIS data implemented over of simulation of monsoon depression in Bay of Bengal development on September 2006 was examined through two numerical control and 3DVAR experiments. One of them used MODIS humidity profiles and temperature at 14 standard pressure levels. During the time interval between Sept'27 2006 to Sept'30 2006 the control experiment employed the NCEP-FNL analysis associated with the boundary and the model simulations were examined.

In this proposed study the $2^{\text {nd }}$ model ${ }^{[2]}$ used MM5 model. For $30 \mathrm{~km}$ single domain, the model was configured with twenty-three layers(vertical) with a horizontal grid spacing with $130 * 118$ grid cells in the east-west and north-south directions respectively. The NCEP FNL data helped to improve the boundary conditions. For assimilated wind data form DWR and upper air and surface data from IMD, effect of 3DVAR has been observed and calculated for Nov 2002 Cyclone. The first experiment which is called Control (CTRL) which used the NECP FNL data only. This data integrated with MM5 model without any observational data assimilation during time interval Nov $10^{\text {th }} 2002$ to Nov $13^{\text {th }}$ 2002.Because the initial vortex of the cyclone was poor and initially placed wrong. The initial vortex then replaced with a synthetic vortex with correct location and intensity $10^{\text {th }}$ Nov 2002. The IMDVAR experiment utilized the IMD upper and surface air data. The DWRVAR experiment utilized the wind data from DWR along with upper air and surface data from IMD The third model ${ }^{[3]}$ used the NCAR and WRF model. This model configured of 24 vertical levels. The model is having a horizontal resolutions of 36 and $12 \mathrm{~km}$ grid spacing. For the coarser domain this model is having a two-way nesting mode with $118 * 130$ grid cells north-south and east-west directions. For finer domain $271 * 271$ grid cells in the north-south and east-west directions respectively. The CTRL experiment utilized the NCEP -GFS for generating the boundary conditions. This simulations associated with this model were performed from $13^{\text {th }}$ Sept 2005 to $17^{\text {th }}$ Sep 2005. In the $2^{\text {nd }}$ experiment SSM/I model integrated from $13^{\text {th }}$ Sept 2005, 18 UTC to $14^{\text {th }}$ Sep 2005, 00 UTC. This experiment was having without any assimilation associated with observations. From $14^{\text {th }}$ Sept. 00 UTC SSM/I TPW observation has been calculated at every twelve hour interval up to $15^{\text {th }}$ Sept 2005, 00 UTC. The $3^{\text {rd }}$ numerical experiment (ATOVS) is like SSM/I experiment except that it utilized humidity profiles and temperature instead of TPW.

\section{RESULTS AND DISCUSSION}


The root mean square error is calculated for dew point, temperature and wind speed associated with all radiosonde station data available over the Indian domain.

\section{Model I:}

Figure 1 show that 3DVAR run having higher spatial correlation of SLP comparison to the control run .Due to assimilation of humidity profiles and MODIS temperature this model displays a noticeable improving in the space correlation of the SLP field. Because of assimilating of the MODIS observations there is a reduction in the RMS error related to SLP field.
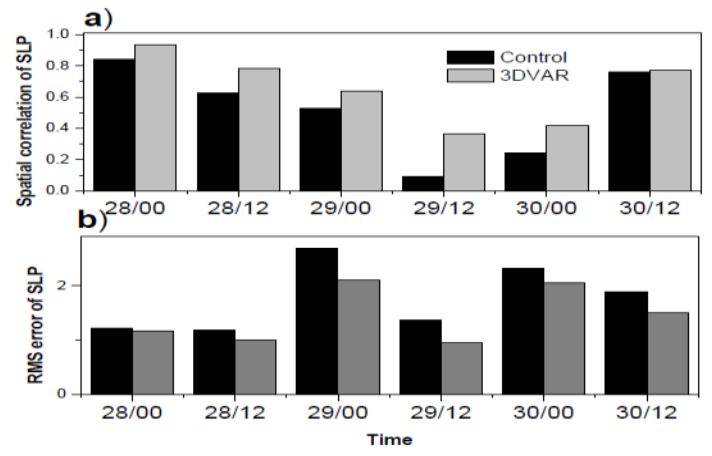

Figure 1: Time series of SPL and RMS error ${ }^{[1] .}$

For further analysis upon quantitative measure like equitable threat score (ETS) and bias scores calculated depending upon the effect of the assimilation of MODIS observations. Figure 2 clearly shows that the values associated with ETS which are generated by the 3DVAR larger than those in the control run.
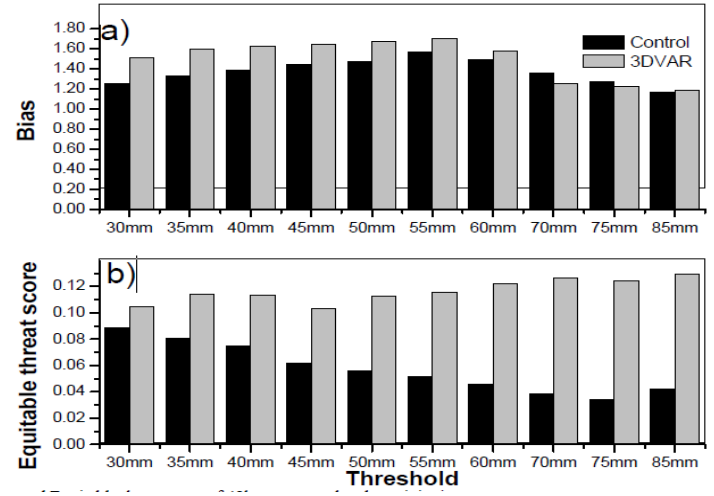

Figure 2: Bias and ETS for accumulated precipitation. ${ }^{[1]}$ The model examined using the FAR with the probability of detection with respect to FAR gives a measure of the false alarms. Figure 3, shows that the FAR associated with control run is more than $D$ DAR run for all threshold values. However, the difference between FAR in control and 3DVAR runs with the increase in threshold values shows an increase in magnitude.
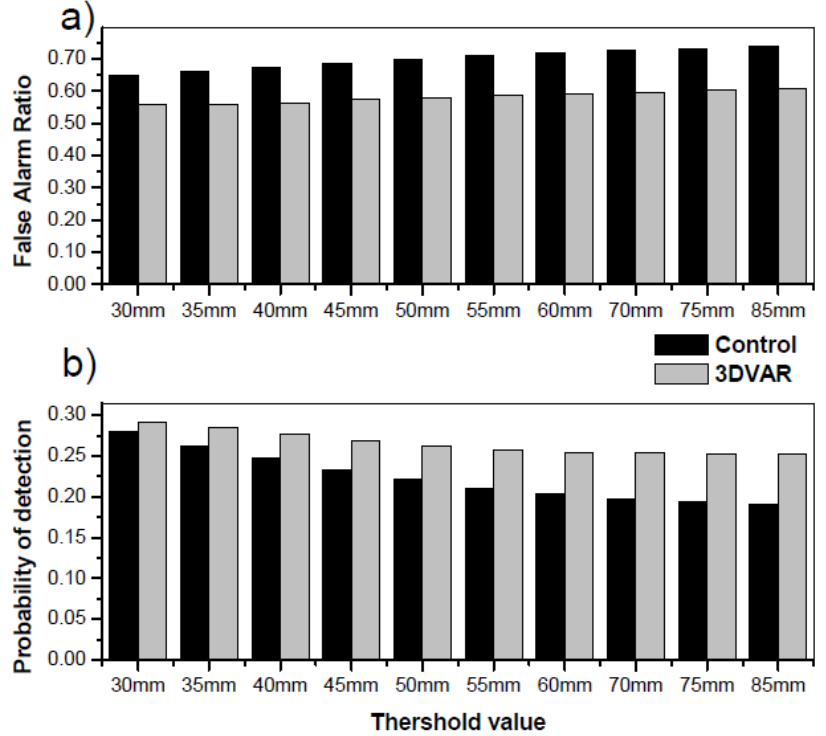

Figure 3: FAR and POD of precipitation ${ }^{[1]}$.

\section{Model II:}

Bias and ETS are supportive for estimating non-probabilistic, gridded precipitation forecasts. From the 24 hour accumulated precipitation, in this model both observation and model, bias and ETS are calculated. The contingency table used for calculating the equitable threat score and bias values. Figure 4 depicts that the ETS values populated by the DWRVAR are larger than those of the IMDVAR and CTRL runs. Figure 5 provides the bias values with respect to all runs. The bias values populated by DWRVAR are much greater than that of the CTRL run and closer to 1 . This indicates that the DWRVAR run has upgraded the precipitation forecast of the model associated to the control run. The IMDVAR run shows lower bias values compared to the other two runs over all the times. Figure 6 explains the false alarm ratio which calculates the number of the false alarms.

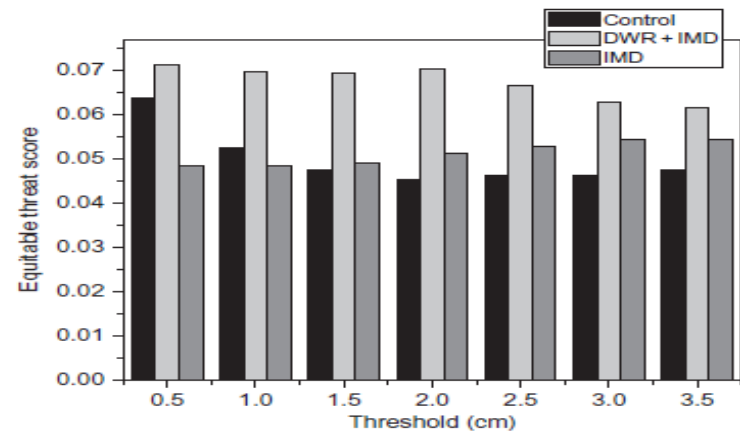

Figure 4 - ETS of control for runs ${ }^{[2]}$.

Published By:

Blue Eyes Intelligence Engineering and Sciences Publication

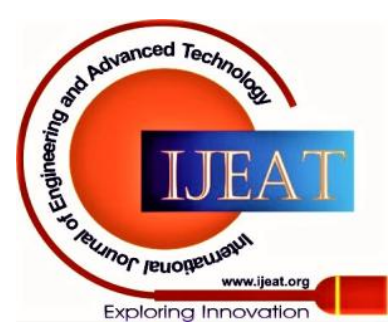



in the Indian Ocean

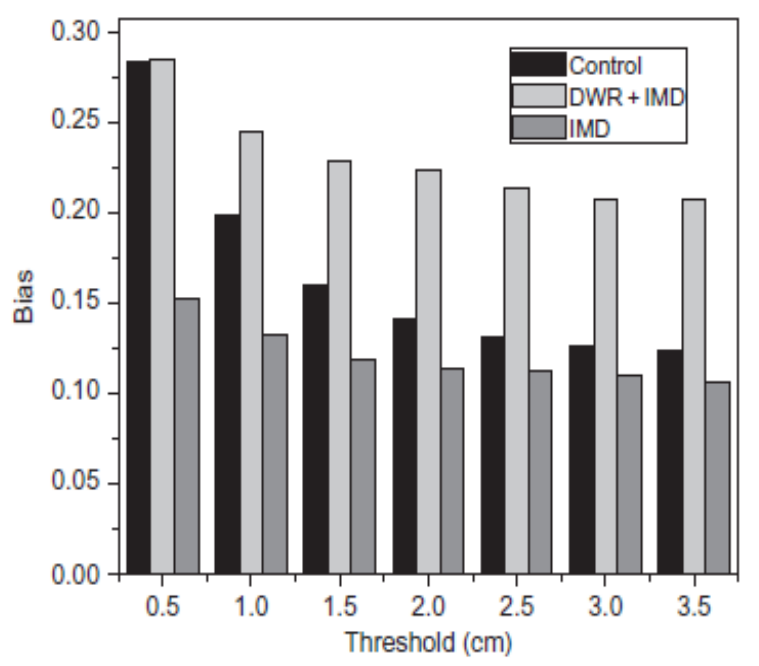

Figure 5 - Bias with respect to threshold. ${ }^{[2]}$

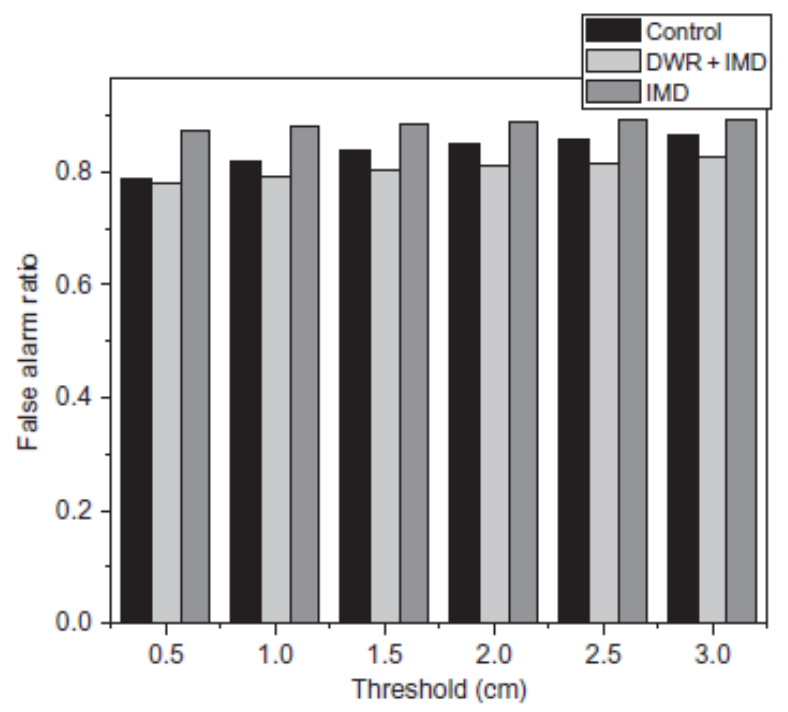

Figure 6 - FAR of all models. ${ }^{[2]}$

\subsection{Model III}

Figure 7 demonstrates the ETS and bias scores calculated for experiments depending upon the 48-hour accumulated precipitation related to TRMM observations. For the lower threshold rainfall values, it can be concluded that the ATOVS experiment shows greater skill of forecast with respect to the SSMI and CTRL experiments. When the threshold rainfall value increases, it can be clearly seen that the forecast skill associated with ATOVS experiment decreases. The experiment that related to assimilation of SSM/I parameters, total precipitable water shows greater ability in precipitation forecast at lower threshold values with respect to the CTRL run.
In Figure 7 the bias scores disclose that the CTRL, SSMI, and ATOVS experiments are over predicting the strength of rainfall associated with all the threshold values of rainfall.

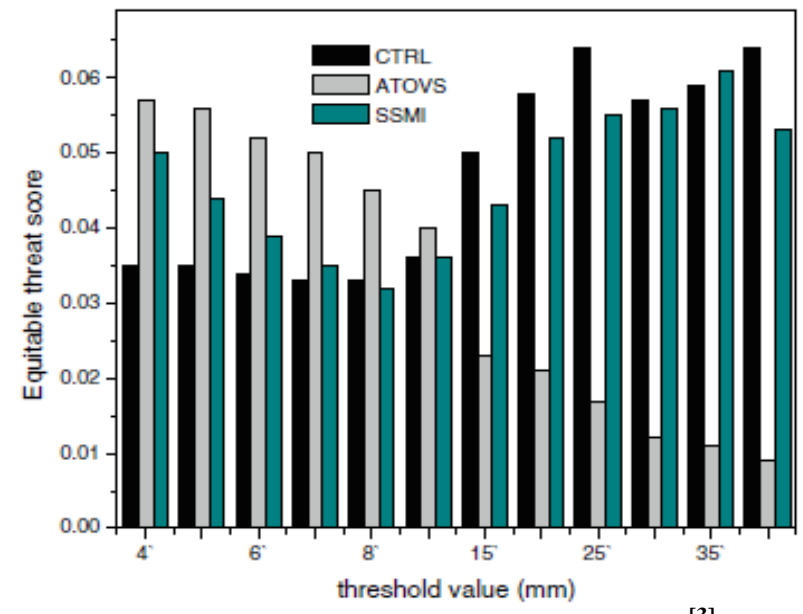

Figure 7 - ETS of the three experiments ${ }^{[3]}$

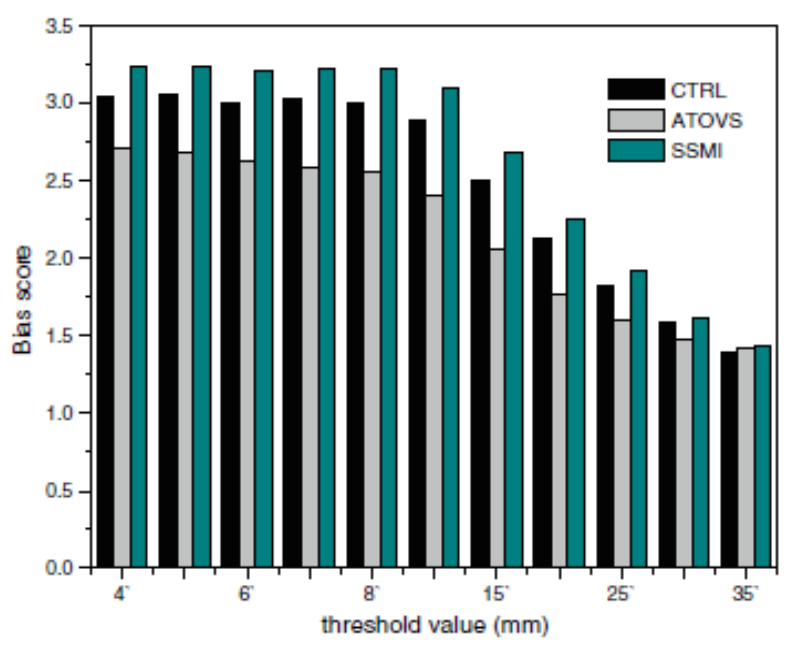

Figure 8 - Bias score ${ }^{[3]}$

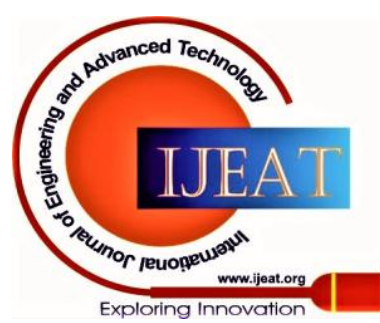




\section{A COMPARATIVE SUMMARY}

\begin{tabular}{|c|c|c|c|c|c|}
\hline Model & Dataset & $\begin{array}{l}\text { Geographical } \\
\text { Locations }\end{array}$ & Advantages & Disadvantages & Parameters \\
\hline Model I & $\begin{array}{l}\square \text { National Center for } \\
\text { Atmospheric Research } \\
\text { Weather Research and } \\
\text { Forecast Model } 2.2 \\
\square \quad 28 \text { Vertical Layer } \\
\square 36 \text { horizontal grid } \\
\square \text { 129*119 grid space. } \\
\square \text { MODIS satellite data. } \\
\square 14 \quad \text { Standard pressure } \\
\text { points. }\end{array}$ & $\begin{array}{lr}\text { North East Bay } \\
\text { Of Araca } & \mathrm{n} \\
\text { coast } 18.0^{0} & \mathrm{~N} \\
\text { and } 89.0^{0} \mathrm{E} . & \end{array}$ & $\begin{array}{l}\text { ETS shows higher } \\
\text { values for run with } \\
\text { MODIs temperature. } \\
\text { POD of precipitation } \\
\text { also increases with } \\
\text { 3DVAR run }\end{array}$ & $\begin{array}{l}\text { For pressure } \\
200 \mathrm{hPa} \text { RMS } \\
\text { error of dew } \\
\text { point } \\
\text { temperature is } \\
\text { high. }\end{array}$ & $\begin{array}{l}\text { 3DVAR run has higher } \\
\text { spatial correlation of SLP } \\
\text { compared to the control run } \\
\text { False alarm ratio for control run is } \\
\text { greater in comparison to the 3DVAR } \\
\text { run for all the threshold values. } \\
\text { Time average rms value } \\
\text { reduced due to assimilation of the } \\
\text { MODIS } \\
\text { observations }\end{array}$ \\
\hline Model II & $\begin{array}{l}\square \text { MM5 Model } \\
\square \text { 23 Vertical Layer } \\
\square \text { 30KM horizontal Grid } \\
\square \text { 118*130 GRID Cell. } \\
\square \text { DWR used for WIND data } \\
\text { with IMD used for } \\
\text { surface and upper air } \\
\text { surface. }\end{array}$ & $\begin{array}{l}750 \mathrm{Km} \text { South } \\
\text { and south west } \\
\text { of Kolkata. } \\
\text { Date: } 10^{\text {th }} \text { Nov. } \\
2002\end{array}$ & $\begin{array}{l}\text { Improvements in } \\
\text { simulations of: } \\
\square \text { Velocity } \\
\square \text { Temperature. } \\
\square \text { Wind speed. } \\
\square \text { Spatial distribution. } \\
\square \text { Precipitations. }\end{array}$ & $\begin{array}{l}\text { Spatial } \\
\text { Limitation of } \\
\text { assimilated } \\
\text { DWR data }\end{array}$ & $\begin{array}{l}\text { SLP: } \\
\text { CTRL: } 0.6872 \\
\text { IMDVAR: } 0.6947 \\
\text { DWRVAR: } 0.7620 \\
\text { False Alarm Ratio: } \\
\text { CTRL, IMDVAR > DWRVAR } \\
\text { RMSE: } \\
\text { CTRL:2.21 hPa } \\
\text { IMDVAR: } 2.86 \mathrm{hPa} \\
\text { DWRVAR: } 2.31 \mathrm{hPa}\end{array}$ \\
\hline Model III & $\begin{array}{l}\text { NCAR-WRF model. } \\
24 \text { Vertical Layer. } \\
130 * 118 \text { grid cells coarser } \\
\text { domain. } \\
271 * 271 \text { grid cells finer } \\
\text { domain. }\end{array}$ & $\begin{array}{l}\text { September } 2005 . \\
\text { Arabian Sea. }\end{array}$ & $\begin{array}{l}\square \text { CTRL and SSMI } \\
\text { experiments have } \\
\text { simulated a } \\
\text { relatively more } \\
\text { active system } \\
\text { compared to the } \\
\text { central pressure of } \\
\text { the ATOVS } \\
\text { experiment } \\
\square \text { It has relatively } \\
\text { stronger north } \\
\text { easterlies, north of } \\
\text { depression center } \\
\text { at the initial time } \\
\text { when compared to } \\
\text { the ATOVS } \\
\text { experiment. } \\
\text { The rainfall intensity } \\
\text { improved by using } \\
\text { proposed model } \\
\text { For day one of the } \\
\text { forecast, } \\
\text { improvement } \\
\text { parameter is more } \\
\text { positive over the } \\
\text { regions of } \\
\text { maximum } \\
\text { precipitation for } \\
\text { both the SSMI and } \\
\text { ATOVS } \\
\text { experiments. } \\
\text { Intense warm core at } \\
\text { mid-tropospheric } \\
\text { levels }\end{array}$ & $\begin{array}{l}\text { ATOVS } \\
\text { experiment } \\
\text { shows slightly } \\
\text { lower values for } \\
\text { "bias score", as } \\
\text { compared to the } \\
\text { CTRL, SSMI } \\
\text { experiment. } \\
\text { CTRL and SSMI } \\
\text { runs had clearly } \\
\text { overestimated } \\
\text { the relative } \\
\text { vorticity values } \\
\text { associated with } \\
\text { the depression } \\
\text { when compared } \\
\text { to the ATOVS } \\
\text { run. }\end{array}$ & $\begin{array}{l}\text { Mean sea level pressure: } \\
\text { CTRL and SSMI (996 hPa) more } \\
\text { accurate ATOVS (998 hPa) } \\
\text { RMSE Error in wind speed: } \\
\text { ATOVS reducing the error } \\
\text { values as compared to other runs } \\
\text { ETS: } \\
\text { ATOVS experiment demonstrates } \\
\text { slightly lower values for "bias score", } \\
\text { as compared to other runs } \\
\text { Relative vorticity: } \\
\text { CTRL and SSMI runs shows } \\
\text { overestimated the relative vorticity } \\
\text { values of depression when compared } \\
\text { to the other run }\end{array}$ \\
\hline
\end{tabular}

\section{Table- I: Comparison of three models.}

\section{CONCLUSION}

In this paper, we have compared the results of the impact of assimilation of multiple proposed techniques with use of 3DVAR assimilation using MODIS temperature, Doppler Weather Radar (DWR), Advanced TIROS Vertical Sounder (ATOVS) temperature and total precipitable water (TPW). The comparison has been performed on the basis of rain fall, wind speed, Mean sea level pressure, ETS, Relative vorticity and false alarm ratio. In the future study we will propose an

efficient model, for accurate prediction of cyclones with less error rates.
Published By:

Blue Eyes Intelligence Engineering

and Sciences Publication (c) Copyright: All rights reserved.

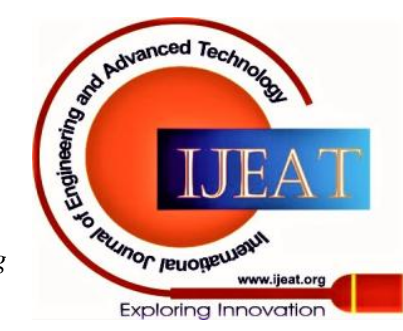




\section{REFERENCES}

1. The Impact of Assimilation of MODIS Observations Using WRF-VAR for the Prediction of a Monsoon Depression During September 2006 M. Govindankutty1, A. Chandrasekar, A.K. Bohra, John P. George and Munmun Das Gupta The Open Atmospheric Science Journal 2(1):68-78 · June 2008.

2. Impact of 3DVAR assimilation of Doppler Weather Radar wind data and IMD observation for the prediction of a tropical cyclone $\mathrm{M}$. Govindankutty, A. Chandrasekar and Devendra Pradhan International Journal of Remote Sensing, Volume 31,July 2010, Issue 24

3. Effect of 3DVAR assimilation of MODIS temperature and humidity profiles on the dynamic and thermodynamic features of three monsoon depressions over the Bay of Bengal

4. M. Govindankutty A. Chandrasekar Meteorology and atmospheric physics (Print). 2010, Vol 107, Num 1-2, pp 65-79, 15 p ; ref : 1/4 p

5. Ide $\mathrm{K}$, Courtier $\mathrm{P}$, Ghil $\mathrm{M}$, Lorenc AC. Unified notation for data assimilation: Operational, sequential and variational. J Meteor Soc Jpn 1997; 75: 181-89.

6. Barker DM, Huang W, Guo YR, Bourgeois AJ, Xiao QN. A Three dimensional Variational (3DVAR) system with MM5: Implementation and Initial results. Mon Weather Rev 2004; 132: 897-914.

7. Gu J, Xiao Q, Kuo YH, Barker DM, Xue J, Ma X. Assimilation and simulation of typhoon Rusa (2002) using the WRF system. Adv Atm Sci 2005; 22: 415-27.

8. Zhang H, Xue J, Zhu G, Zhang S, Wu X, Zhang F. Application of direct assimilation of ATOVS microwave radiances to typhoon track predictions. Adv Atm Sci 2004; 21: 283-90.

9. [8] A Bhilash, S., Das , S., Kalsi , S.R., Dasgupta , M., M Ohankumar , K., G Eorge , J.P., B Anerjee, S.K., T Hambi , S.B. And P Radhan , D., 2007, Impact of Doppler radar wind in simulating the intensity and propagation of rainbands associated with mesoscale convective com-plexes using MM5-3DVAR system. Pure and Applied Geophysics, 164, pp. 1491-1509.

10. B Arker , D.M., H Uang, W., G Uo, Y.R. And A L B Ourgeois , 2003, A Three Dimensional Variational (3DVAR) data assimilation scheme for use with MM5. NCAR technical note, NCAR/TN-453 p STR, p. 68.

11. D AVIS, C.A. and LOWNAM ,S., 2001, The NCAR-AFWA tropical cyclone bogussing scheme.Air Force Weather Agency Report, NCAR Boulder, CO, 13 pp.

\section{AUTHORS PROFILE}

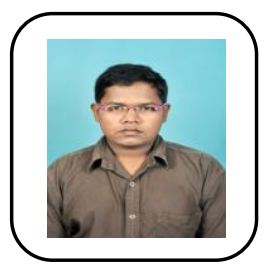

Mr.Satya Sundar Mallick is currently associated as a research scholar with KIIT Deemed University, Bhubaneswar. He completed his M.Tech in Computer Science from KIIT Bhubaneswar. His research area includes Wireless sensor networks, Weather simulation models.

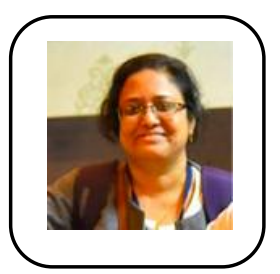

Dr. Monideepa Roy did her Masters in Mathematics from IIT Kharagpur, and her PhD in CSE from Jadavpur University. Currently she is an Associate Professor at KIIT Deemed University, Bhubaneswar since the last eleven years. Her areas of interest include Wireless Networks, Mobile Computing and WSNs, and Cognitive WSNs, AI, CNN, Remote Sensing, Image Processing and Recommender Systems . At present she has eight research scholars working with her in these areas. She has several publications in conferences and journals. She has been the Organizing Chair of various international conferences and has also organized many workshops and seminars.

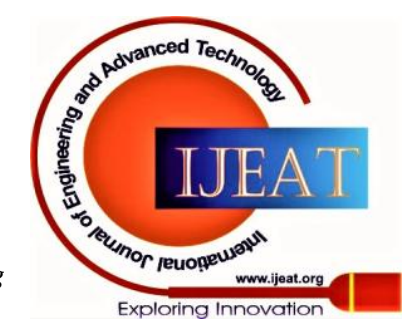

